\title{
Karasal algılayıcı ağlarda gözlemleme için enerji etkin TDMA erişim tekniği
}

\author{
Muhammed Enes BAYRAKDAR* \\ Düzce Üniversitesi, Teknoloji Fakültesi, Bilgisayar Mühendisliği Bölümü, \\ Merkez Kampüs, Düzce. \\ Geliş Tarihi (Received Date): 13.02.2019 \\ Kabul Tarihi (Accepted Date): 26.06.2019
}

\section{Özet}

Algılayıcı ăgların uygulama alanlarından biri olan karasal algılayıcı ăglar, gözlemleme işlemleri için günümüzde yaygın olarak kullanılmaktadır. Kablosuz algılayıcı ağlar, belirli bir bölgenin sicaklık, nem, basinç, hareket gibi karakteristiklerini incelemek amacıyla küçük bir gömülü cihaz üzerine yerleştirilmiş farklı algılayıcıların birleşimi olarak karşımıza çıkmaktadır. Sürekli olarak belirli bir bölgeyi izlemek için kablosuz algılayıcı ă̆ın bu bölgelerin kesişme noktalarında yer alması gerekmektedir. Bu makalede, kablosuz algılayıcı ağına dayalı bir gözlemleme sistemi oluşturulmuştur. Kırsal bölgelerdeki belirli bir arazinin ne tür meyve - sebze yetiştiriciliğine uygun olduğunu tespit etmek amacılla sicaklık, nem, basınç, vb. değerlerin sezilmesi düşünülmüşü̈r. Gözlemleme için kullanılan algılayıcı düğümler benzetim ortamında geliştirilmiştir. Kablosuz algılayıcı ăg düğümlerinin yapısı, donanımı ve iş akışı tasarlanmıştır. Tasarlanan sistemin enerji verimli olarak çalışması ve paket çarpışmalarının yaşanmaması için ortam erişim tekniği olarak TDMA protokolü seçilmiştir. Benzetim sonuçlarl, algılayıcı ă̆ın ortam bilgilerini hızl bir şekilde toplama ve veriyi gerçek zamanl olarak işleme merkezine aktarma yeteneğine sahip olduğunu göstermektedir. Ayrıca, önerdiğimiz sistem karasal alandaki kablosuz algılayıcı ă̆ların kullanışlılığını ortaya koymaktadır.

Anahtar kelimeler: Algılayıcı ăg, ortam erişim, karasal.

\footnotetext{
* Muhammed Enes BAYRAKDAR, muhammedbayrakdar@duzce.edu.tr, https://orcid.org/0000-0001-9446-0988
} 


\title{
Energy efficient TDMA access technique for surveillance in terrestrial sensor networks
}

\begin{abstract}
The terrestrial sensor networks, which are one of the application areas of sensor networks, are now widely used for monitoring and security operations. The wireless sensor networks are a combination of different sensors placed on a small embedded device to examine characteristics of a given region such as temperature, humidity, pressure, movement. The wireless sensor network must be located at the intersection points of these zones to continuously monitor a specific area. In this article, a monitoring system based on the wireless sensor network is created. The sensor nodes used for monitoring were developed in a simulation environment. The structure, hardware and workflow of wireless sensor network nodes are designed. TDMA protocol has been chosen as the medium access technique in order to ensure that the designed system operates in an energy-efficient manner and that packet collisions are not experienced. The simulation results show that the sensor network has the ability to quickly collect media information and transmit data to the processing center in real time. In addition, the system we proposed suggests the usefulness of wireless sensor networks in the terrestrial area.
\end{abstract}

Keywords: Sensor network, medium access, terrestrial.

\section{Giriş}

Kablosuz algılayıcı ağların benzersiz özellikleri, klasik kablosuz ağların tüm yönleriyle yeniden düşünülmesini gerektirmektedir [1,2]. Bunlar arasında, algılayıcı ağlarda temel ve hala keşfedilmemiş bir sorun olan ideal paket boyutunun belirlenmesi işlemi bulunmaktadır [3,4]. Özellikle, düşük güçlü iletişim kısıtlamaları ve düşük maliyetli algılayıcı düğümlerin tasarım özellikleri nedeniyle iletişimde çapraz katman etkilerinin de incelenmesini gerektirmektedir [5,6]. Algılayıcı ağların enerji verimli olarak çalışabilmesi için, ideal paket boyutunun ve ortam erişim tekniğinin doğru bir şekilde değerlendirmesi gerektirmektedir [7].

Geleneksel olarak paket büyüklüğü optimizasyonu, belirli bir verimlilik ölçütüne dayalı olarak paketin noktadan noktaya başarılı bir şekilde aktarılması gerektiği göz önüne alınarak gerçekleştirilir [8]. Bununla birlikte, geleneksel yaklaşımda kablosuz algılayıcı ağ iletişiminin çoklu atlama ve geniş yayın özelliklerinin etkisi de hesaba katılmaktadır $[9,10]$. Paket büyüklüğünün, iletişimin güvenilirliğini doğrudan etkilediği iyi bilinmektedir [11]. Bunun yanında, çoklu atlama algılayıcı ağlarda, iletişim bağlantılarının kalitesi ağda oluşturulan rotalara ve kullanılan ortam erişim tekniğine bağlıdır [12]. Ayrıca, paylaşılan kablosuz ortam için rekabet eden komşu düğümlerin varlığı, iletişim başarısını önemli ölçüde bozmakta ve iletişim performansını etkilemektedir [13]. Gerçekleştirilen iletişimin başarısı, hem kablosuz kanalın özelliklerine hem de kullanılan hata kontrol tekniğine bağlıdır [14]. İletişimin farklı katmanlarının bir araya gelmesinden kaynaklanan bu gibi faktörler göz önüne alındığında, algılayıcı ağlar için paket boyutu optimizasyonu, ortam erişim tekniği seçimi ve çapraz katman değerlendirmesi çok önemlidir [15]. 
Paket boyutu optimizasyonu ve ortam erişim tekniği seçimindeki zorluklardan birisi de algılayıcı ağların kendi doğal yapısından kaynaklanmaktadır [16]. Algılayıcı ağlar, son derece karmaşık kablosuz algılayıcı düğümlerin geliştirilmesinden bu yana geniş uygulama alanları bulmuştur [17]. Algılayıcı ağlar genel olarak ormanlar, fabrikalar, binalar, vb. karasal alanlarda yaygın olsa da farklı alanlarda da geniş bir yelpazede kullanılmaktadır [4]. Son zamanlarda, algılayıcı ağ araştırması sualtı ve yeraltı ortamlara da yayılmıştır [9]. Sualtı kablosuz algılayıcı ağları, çok düşük bant genişliği ve yüksek hata oranı sualtı kanalları ile karakterize edilmektedir [12]. Benzer şekilde, son zamanlarda kablosuz yeraltı algılayıcı ağ uygulamaları ve gereksinimleri de araştırılmaktadır [3]. Bu ağlar, kanal özellikleri açısından ek zorlukları da beraberinde getirmektedir [6]. Sonuç olarak, bu ortamlar için de optimum paket boyutu ve ortam erişim tekniği isabetli olarak belirlenmelidir [15].

Duan ve arkadaşları, potansiyel bilgileri zamanında toplayabilen karasal boru koruma ekipmanlarını izlemek için bir sistem tasarlamışlardır [18]. Geliştirdikleri sistemde, katot korumasının koruma modunda talep üzerine ince ayar yapabilmektedirler. Sistemlerinde, potansiyel verileri toplamak ve uzak veri iletimini gerçekleştirmek için kablosuz algılayıcı ağları ve GPRS teknolojisini entegre etmişlerdir. Enerji tüketimini etkin bir şekilde düşürmek, donanım bileşenlerinin seçiminde güç tasarrufu sağlamak ve çarpışmayı önlemek için TDMA protokolünü kullanmışlardır. Veri iletimi ve düşük güç tasarrufu bakımından \%96 civarı sonuçlar elde etmişlerdir. Ayrıca, karasal boru hattının fiziksel hatalarını zamanında tespit etme ve talep üzerine kablosuz algılayıcı ağlarını kontrol etme gereksinimlerini karşılamışlardır [18].

Stuntebeck ve arkadaşları, kablosuz yeraltı algılayıcı ağı kavramı üzerine uygulamaları tartışmışlardır [19]. Yeraltı ortamında yaygın olarak bulunan karasal kablosuz algılayıcı ağ donanım çözümlerinin kullanımının alt yapısını incelemişlerdir. İki farklı yeraltı algılayıcı düğüm arasında ve bir yeraltı algılayıcı düğüm ile yer üstü algılayıcı düğüm arasında gerçekleşen iletişim için paket hata oranı ve alınan sinyallerin alınan sinyal gücü üzerine incelemeler yapmışlardır [19].

Alhashimi ve arkadaşları, bağımsız algılayıcı kaynak bilgisi gerektirmeyen mesafe algılayıcıları için yeni bir kalibrasyon prosedürü tanımlamışlardır [20]. Önerdikleri çalışmada, algılayıcıların doğrusal hareketi izlediklerini ve nesnelerin hareket etmediğini vurgulamışlardır. Prosedürlerini sadece genel bir mesafe algılayıcı parametrelerini tahmin etmek için değil, aynı zamanda robotik uygulamalarda en yaygın kullanılan algılayıcıları entegre etmek ve algılayıcıların içsel parametrelerini öğrenmek için tasarlamışlardır. Yaptıkları testlerin, doğrusal hareketler varsayımını ihlal etmeye karşı yüksek sağlamlık gösterdiğini vurgulamışlardır [20].

Tondwalkar ve arkadaşları, algılayıcı düğümlerin hareketli ve sabit olduğu algılayıcı ağlar aracılığıyla lokalizasyon hizmeti tasarlamayı amaçlamışlardır [21]. Kablosuz algılayıc1 ağ uygulamalarının çoğunluğunun, algılayıcı düğümlerin esas fiziksel konumlarının güvenilir bilgisini gerektirdiğini vurgulamışlardır. Pozisyon hesaplaması için üçgenleme yöntemini kullanmışlardır. Güvenilir konum bilgisi elde etmek için, hesaplanan pozisyonun aksine gerçek pozisyonun kök minimum ortalama kare hata analizi yönteminden faydalanmışlardır [21]. 
Bu makalede, kablosuz algılayıcı ağına dayalı bir gözlemleme sistemi oluşturulmuştur. Gözlemleme için kullanılan algılayıcı dügüumler benzetim ortamında geliştirilmiştir. Kablosuz algılayıcı ağ dügümlerinin yapısı, donanımı ve iş akışı tasarlanmıştır. Tasarlanan sistemin enerji verimli olarak çalışması ve paket çarpışmalarının yaşanmaması için ortam erişim tekniği olarak TDMA protokolü seçilmiştir. Tüm tasarım aşamaları Riverbed Modeler yazılımı kullanılarak gerçekleştirilmiş̧ir [22]. Algılayıcı dügüumlerin çarpışmadan kaçınması ve enerji verimli olarak çalışması için TDMA ortam erişim tekniği kullanılarak modellenmişlerdir. Benzetim modeli sonuçları incelendiğinde, karasal algılayıcı ağın sezilen verileri çok düşük bir gecikme ile topladığ 1 ve bu verileri hızlı bir şekilde çevrimiçi izleme merkezine gönderdiği görülmektedir. Ayrıca, önerilen araştırma alanındaki kablosuz algılayıcı ağların kullanışlılığını ortaya koymaktadır. Önerdiğimiz sistem, kırsal alanlarda meyve, sebze yetiştiriciliğinde ortamın sicaklık, nem gibi özelliklerinin denetimi ve izlemesi için kullanılabileceği gibi belirli bir bölgenin farklı özelliklerinin kontrolü için de kullanılabilecektir.

\section{Teorik model ve benzetim modeli çalışmaları}

Çalışmamızda, karasal algılayıcı ağlarda gözlemleme için enerji etkin erişim tekniğinin tasarımı ve benzetimi yapılmıştır. Ağ yapımızın temeli ve tasarımı tamamlandıktan sonra, Riverbed Modeler yazılımı ile benzetimi yapılmıştır. Senaryo olarak, kırsal bölgelerde belirli bir arazinin ne tür meyve veya sebze yetiştiriciliğine uygunluğunu tespit etmek için sıcaklık, nem, basınç, vb. özelliklerinin algılayıcı düğümler yardımıyla uzun süreli gözlemlenmesi düşünülmüştür.

Riverbed Modeler, hem benzetim modellerini yapılandırmak hem de ağ senaryoları geliştirmek için grafiksel bir kullanıcı arabirimi sunmaktadır. Kablosuz ağın yapılandırması üç aşamada gerçekleştirilmektedir; ağ aşaması, düğüm aşaması ve işlem aşaması. A ̆g aşamasında, ağın topolojisi oluşturulmaktadır. Düğüm aşaması, düğümün davranışını tanımlamaktadır ve düğümün farklı modülleri arasında akan verileri kontrol etmektedir. Süreç aşaması, durumlar ile kullanılan durum makineleri ve aralarındaki geçişler ile karakterize edilmektedir. Riverbed Modeler benzetim yazılımının kaynak kodu Proto C programlama dilinde yazılmaktadır.

\subsection{Karasal algılayıcı ă tasarım ve benzetimi}

Şekil 1'de görülmekte olan karasal algılayıcı ağ tasarımında, tarıma uygunluk tespitinin yapılması için kırsal bir bölgeye yerleştirilmiş çok sayıda algılayıcı bulunmaktadır. Algılayıcılar kendi aralarında tasarsız (ad-hoc) olarak haberleşmektedir.

Algılayıcı düğümler, gerektiği durumlarda da birbirleri üzerinden haberleşerek verilerini toplayıcı istasyona aktarmaktadırlar. Ortam erişim tekniği olarak çarpışma içermediğinden dolayı enerji etkin bir protokol olan TDMA tabanlı ortam erişim tekniği kullanmaktadırlar. Karasal algılayıcı dügüumlerden gelen verileri toplama görevini toplayıcı istasyon üstlenmektedir. 


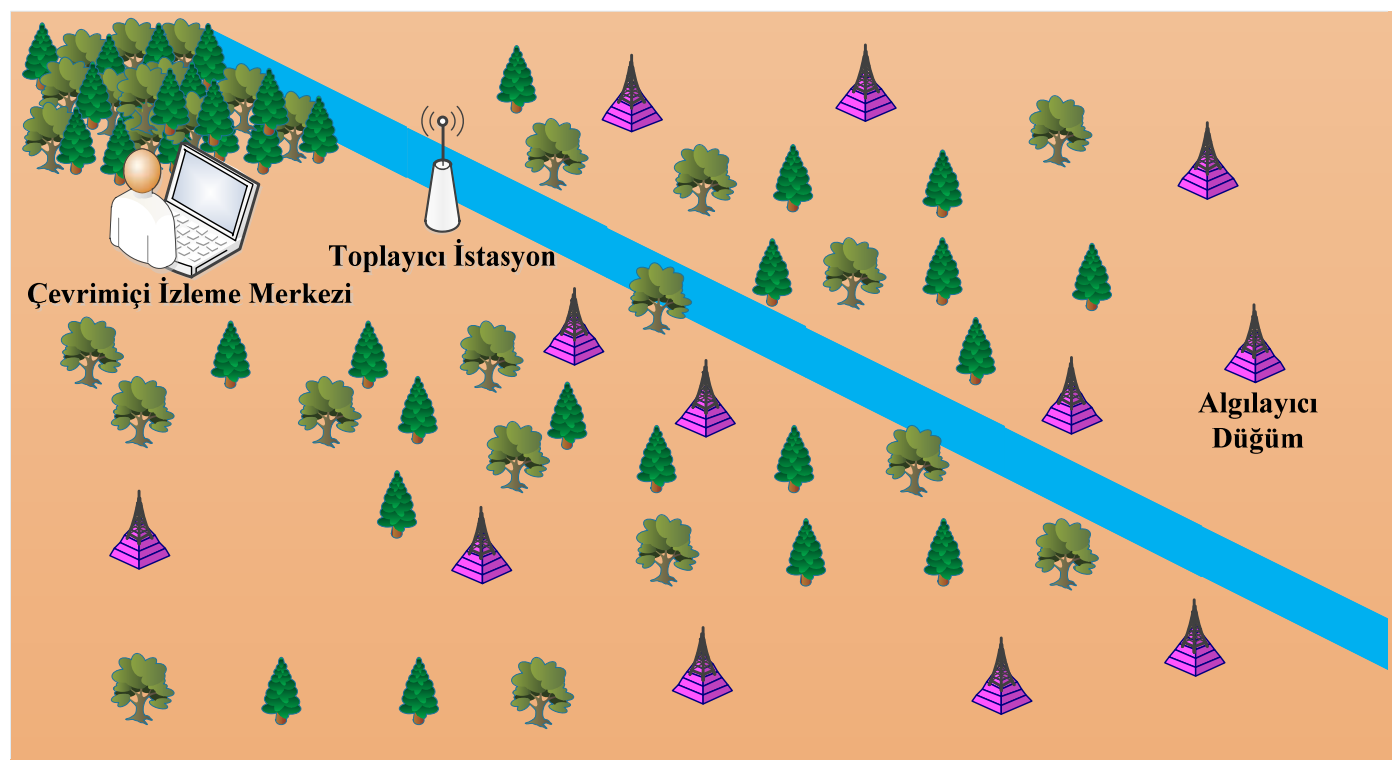

Şekil 1. Karasal algılayıcı ağ tasarımı.

Birbirleri üzerinden haberleşerek verilerini toplayıcı istasyona aktardıkları için merkezi bir koordinatöre düğüme ihtiyaç duymamaktadırlar. Toplayıcı istasyonun topladığ veriler, civarda bulunan herhangi bir çevrimiçi izleme merkezinden izlenmekte ve takip edilmektedir. Toplayıcı istasyon, çevredeki algılayıcı düğümlerden gelen sıcaklık, nem, basınç vb. verileri toplamaktadır.

Tablo 1. Karasal algılayıcı ağ benzetim parametreleri.

\begin{tabular}{|c|c|}
\hline Parametre & Değer \\
\hline Veri iletim hızı & $250 \mathrm{Kbps}$ \\
\hline Paket boyutu & 50 byte \\
\hline Gecikme & $5 \mathrm{us}$ \\
\hline Frekans & $2,4 \mathrm{Ghz}$ \\
\hline Benzetim süresi & $3600 \mathrm{sn}$ \\
\hline Gönderim gücü & $50 \mathrm{~mW}$ \\
\hline Alım gücü & $42,5 \mathrm{~mW}$ \\
\hline Algılayıcı düğ̈m sayısı & 12 \\
\hline
\end{tabular}

Tablo 1'de, karasal algılayıcı ağ benzetim parametreleri gösterilmektedir. Riverbed Modeler yazılımı üzerinde, her bir parametre ve aldığı değerler net bir şekilde ifade edilmiştir. Veri iletim hızı, algılanan verilerin dügümlerden toplayıcı istasyona aktarılma hızını ifade etmektedir ve karasal alanlar için $250 \mathrm{Kbps}$ olmaktadır. Paket boyutu, algılanan verinin sayısal olarak büyüklügüüü temsil etmektedir ve sıcaklık, nem, basınç, vb. veriler için 50 byte yeterli olmaktadır. Gecikme, sezilen bir verinin algılayıcı dügüumden toplayıcı istasyona gönderildiği süredir ve küçük çaplı karasal algılayıcı ağlar için 5 us olmaktadır. Frekans değeri olarak, kablosuz haberleşme için en çok kullanılan 2,4 Ghz seçilmiştir. Benzetim süresi, benzetim yazılımının bu ă̆ yapısını test ettiği süredir ve genel olarak doğru sonuç almak için 3600 sn yeterli olmaktadır. Gönderim gücü ve alım gücü, sezilen verinin gönderilmesi ve alınması için gereken güçtür ve karasal algılayıcı ağlardaki sıcaklık, nem, basınç, vb. veriler için sırasıyla 50 
$\mathrm{mW}$ ve 42,5 mW yeterli olmaktadır. TDMA tekniğgi, 10 - 15 algılayıcı düğüme kadar iyi performans göstermektedir. Bu sebeple algılayıcı düğüm sayısı 12 olarak seçilmiştir.

\subsection{TDMA ortam erişim tekniği}

TDMA sistemler, radyo spektrumunu zaman dilimlerine bölmektedir ve her bir zaman diliminde sadece bir algılayıcı düğüm alma ya da gönderme işlemi yapabilmektedir. $\mathrm{Bu}$ sistem belirli bir zaman bölgesine genişletilirse, birbirinden bağımsız pek çok algılayıcı düğüm aynı ortam üzerinden ve farklı zaman dilimlerinde iletim işlemlerini gerçekleştirebilirler.

TDMA yapısında, veri hızı doğrudan doğruya iletim ortamının bant genişliğine bağlıdır. İletim ortamının bant genişliği çok fazla ise, çok yüksek veri hızlarına ulaşmak mümkündür. $\mathrm{Bu}$ durum, aynı iletim ortamından çok daha fazla algılayıcı düğümün iletim yapabilmesi anlamına gelmektedir. Bant genişliği düşük olan iletim ortamlarında ise daha düşük veri hızlarında iletim yapılabilmektedir.

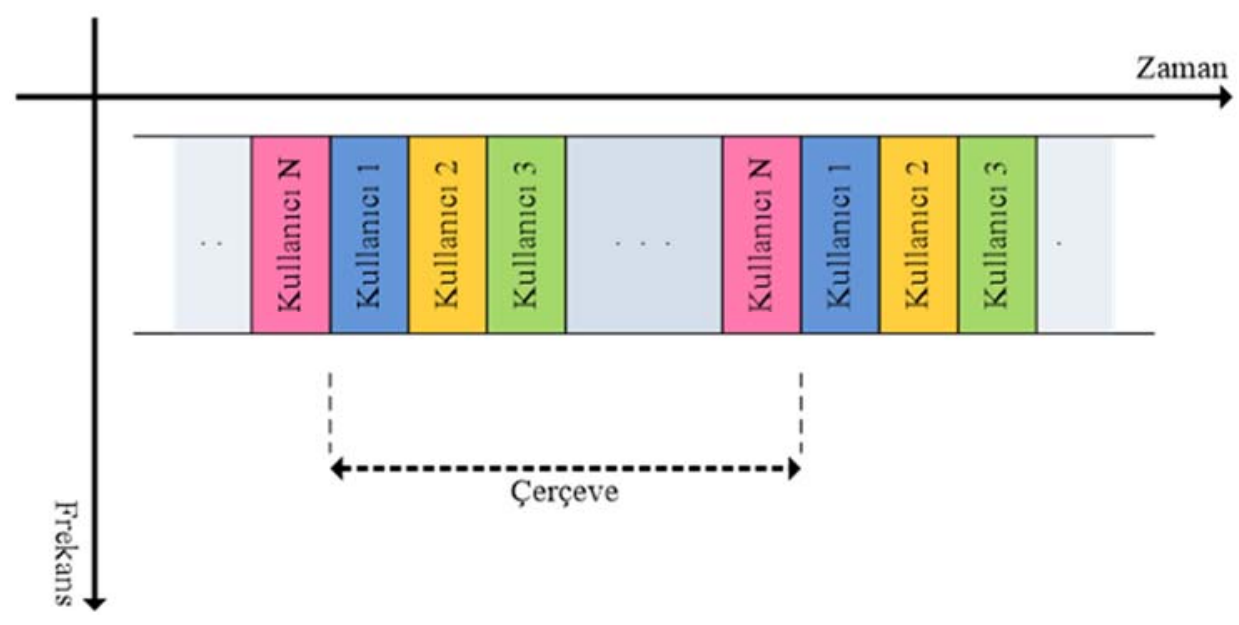

Şekil 2. TDMA ortam erişim tekniği.

Şekil 2'de, her bir algılayıcı düğümün zaman çerçevesindeki bir kanalı kullandığ1 görülmektedir. $\lambda$ üretilen ortalama paket sayısı ve $\mathrm{N}$ kullanıcı sayısı olmak üzere, başarım oranı $\mathrm{G}$ aşağıdaki gibi ifade edilmektedir.

$\mathrm{G}=\lambda * \mathrm{~N}$

Başarım oranı, belirli bir zaman diliminde algılayıcı düğümlerin gönderdiği verilerin toplayıcı istasyon tarafından başarılı bir şekilde alınması olarak ifade edilmektedir. TDMA tekniği çekişme tabanlı bir ortam erişim protokolü olmadığı için, ağa gönderilen TDMA paketleri birbirleriyle çarpışmamaktadır. Bu sebeple, ortalama yük 1'den az olduğunda başarım oranı sunulan yüke eşit olmaktadır. Ortalama yükün 1 ve 1 'den fazla olduğu durumda ise, başarım oranı 1'e eşit olarak kalmaktadır.

Karasal algılayıcı düğümler göz önüne alındığında, enerji tüketiminin yoğun olarak kablosuz haberleşme aşamasında meydana gelmektedir, bunun dişındaki enerji tüketimleri göz ardı edilebilecek seviyededir. S paket iletimi için geçen süre ve $\mathrm{P}$ paket iletim işleminde harcanan güç olmak üzere, enerji tüketimi $\mathrm{E}$ aşağıdaki denklemde olduğu şekilde elde edilmektedir. 
$\mathrm{E}=\mathrm{S} * \mathrm{P}$

Sistemin enerji etkin bir şekilde çalışması için, paket iletiminde harcanan gücün ve sürenin az olması gerekmektedir. Bunu sağlamak için, birbirleri üzerinden haberleştikleri göz önünde bulundurularak dügümmlerin mümkün olduğunca birbirlerine yakın bir konumda yerleştirilmeleri önem arz etmektedir.

\section{Grafiksel sonuçlar}

Algılayıcı ağ yükü 0'dan 1'e doğru artırıldığında, başarım oranı da yaklaşık olarak aynı oranda artmaktadır. Bunun sebebi, karasal algılayıcı ağların ve kablosuz haberleşme ortamlarının doğal yapısından kaynaklanan bozucu etkilerdir. Diğer taraftan, algılayıcı ağ yükü 1 ya da daha fazla olduğunda başarım oranı yaklaşık 1 seviyesinde kalmaktadır. Şekil 3'de, analitik sonuçların benzetim sonuçları ile birebir örtüştüğü net bir şekilde görülmektedir.

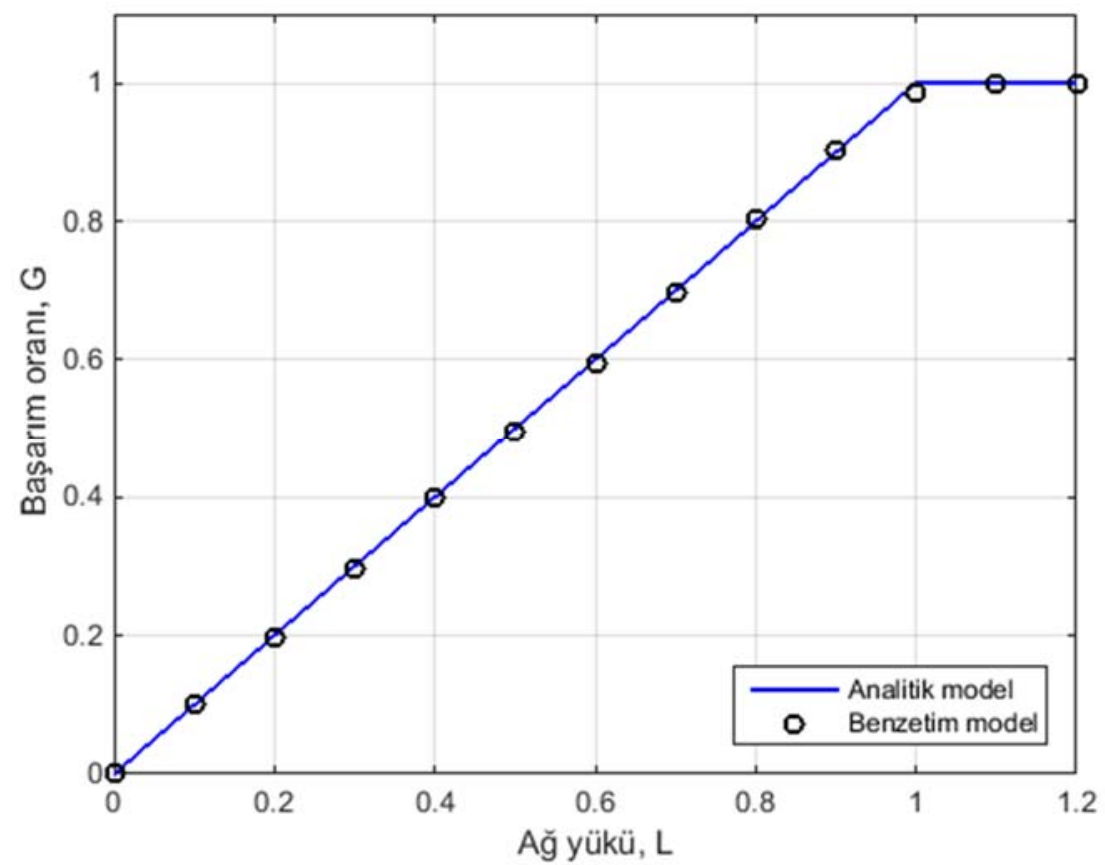

Şekil 3. TDMA başarım oranı.

Algılayıcı ağ yükü 0'dan 3'e doğru artırıldığında, enerji tüketimi de 0'dan 1'e doğru belirli bir oranda artmaktadır. Bunun sebebi, karasal algılayıcı düğümlerden toplanan verilerin artmasına bağlı olarak enerji tüketimi yapmalarıdır. Diğer taraftan, algılayıcı ağ yükü 2,5 veya daha fazla olduğunda enerji tüketimi yaklaşık 0,8 civarında kalmaktadır. Şekil 4'te, analitik sonuçların benzetim sonuçları ile birebir örtüştügü net bir şekilde görülmektedir. 


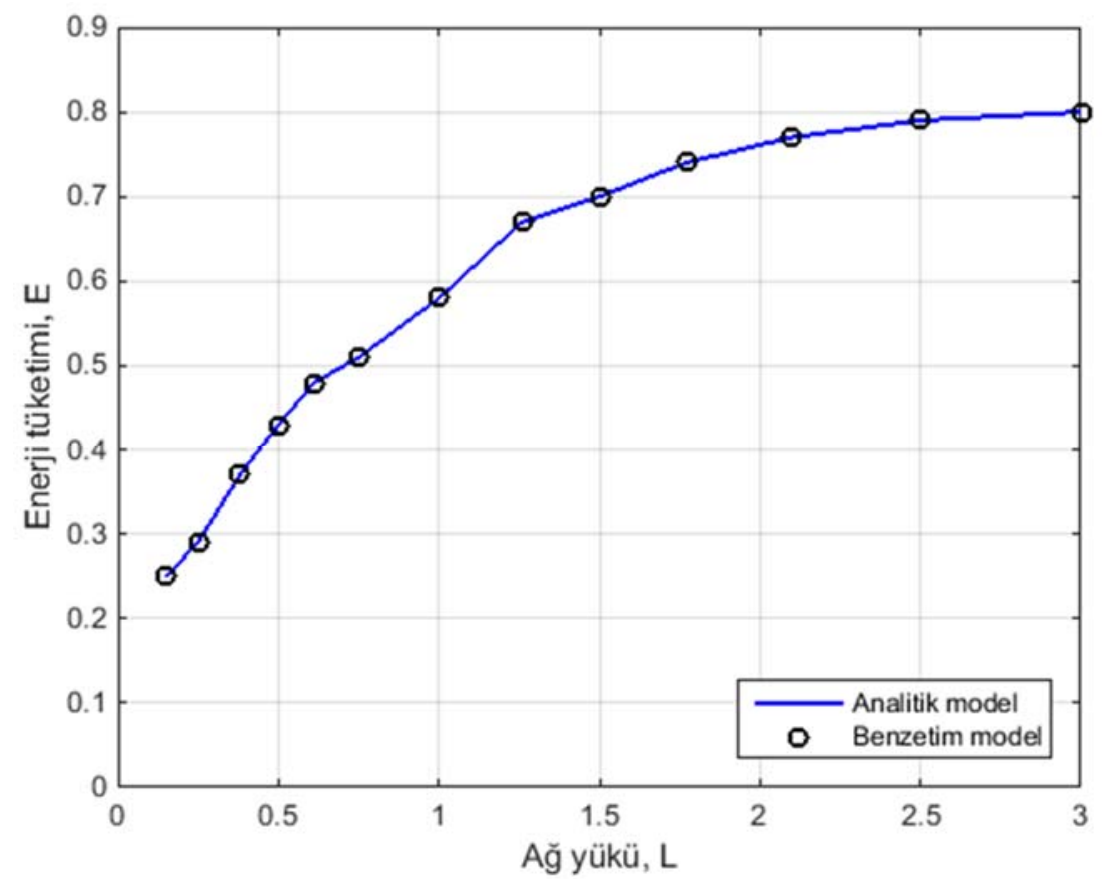

Şekil 4. TDMA enerji tüketimi.

Şekil 3 ve Şekil 4 dikkatli bir şekilde incelendiğinde, benzetim model ve analitik model sonuçlarının çok yakın olması, karasal algılayıcı ağ tabanlı enerji verimli ortam erişim tekniğinin geçerliliğini ortaya koymaktadır. Elde edilen bulgular, benzetim modelini geliştirdiğimiz enerji etkin karasal algılayıcı ağ modelinin hedeflenen nitelikleri sağladığından dolayı gerçek hayattaki ortamlarda da kullanılabileceğini gözler önüne sermektedir.

\section{Bulgular ve tartışma}

$\mathrm{Bu}$ çalışmada, kablosuz algılayıcı ağına dayalı bir gözlemleme sistemi ele alınmıştır. Gözlemleme için kullanılan algılayıcı düğümlerin tasarımı benzetim ortamında yapılmıştır. Kablosuz algılayıcı ağ düğümlerinin yapısı, donanımı ve iş akış1 tasarlanmıştır. Tasarlanan sistemin enerji verimli olarak çalışması için ortam erişim tekniği olarak TDMA protokolü seçilmiştir. Benzetim modelinden elde edilen sonuçlara bakıldığında, önerilen kablosuz karasal algılayıcı ağdaki toplayıcı istasyonun ortamdan sezilen verileri hızlı bir şekilde topladığı ve bu verileri gerçek zamanlı olarak izleme merkezine aktarabildiği görülmektedir. Ayrıca, önerilen araştırma alanındaki kablosuz algılayıcı ağların kullanışlılığını ortaya koymaktadır.

$\mathrm{Bu}$ çalışma temel alınarak, farklı enerji etkin ortam erişim teknikleri kullanılarak gözlemleme uygulamaları gerçekleştirilebilir. Gelecekte bu tarz çalışmaların yapıılması, algılayıcı ağ kullanımının iyi yönlerinin günlük hayatta kullanabileceğimiz yapıya kavuşmasını sağlayacaktır. 


\section{Teşekkür}

Değerli desteklerinden dolayı kıymetli eşim Sümeyye ve kızım Asel'e çok teşekkür ederim. Danışman olarak bana yaptığı katkılardan dolayı Doç. Dr. Ali Çalhan hocama çok teşekkür ederim.

\section{Kaynaklar}

[1] Ahmad, A., Javaid, N., Imran, M., Guizani, M. and Alhamed, A.A., An advanced energy consumption model for terrestrial wireless sensor networks, International Wireless Communications and Mobile Computing Conference (IWCMC), 790-793, Paphos, (2016).

[2] Kato, A., Wakabayashi, H., Hayakawa, Y., Bradford, M., Watanabe, M. and Yamaguchi Y., Tropical forest disaster monitoring with multi-scale sensors from terrestrial laser, UAV, to satellite radar, IEEE International Geoscience and Remote Sensing Symposium (IGARSS), 2883-2886, Fort Worth, TX, (2017).

[3] Descamps, P., Vindevoghel, J., Bouazza, F. and Sawsan, S., Microwave doppler sensors for terrestrial transportation applications, IEEE Transactions on Vehicular Technology, 46, 1, 220-228, (1997).

[4] Bachmann, R.J., Boria, F.J., Ifju, P.G., Quinn, R.D., Kline, J.E. and Vaidyanathan R., Utility of a sensor platform capable of aerial and terrestrial locomotion, IEEE/ASME International Conference on Advanced Intelligent Mechatronics, 1581-1586, Monterey, CA, (2005).

[5] Zhang, C., Terrestrial mobile networks for Air-to-ground communications of the general aviation, International Conference on Wireless Communications and Signal Processing (WCSP), 1-5, Nanjing, (2011).

[6] Babbitt, J., O'Dell, S. and Xu, Y., Optimizing terrestrial transport architecture in satellite telephony networks, IEEE Wireless Communications and Networking Conference, 164-168, New Orleans, LA, USA, (1999).

[7] Dean, R.A., Satellite/terrestrial interoperation in personal communications networks, Proceedings of 3rd IEEE International Conference on Universal Personal Communications, 450-454, San Diego, CA, USA, (1994).

[8] Kapovits, A., Satellite communications integration with terrestrial networks, China Communications, 15, 8, 22-38, (2018).

[9] Baras, J.S., Ball, M., Roussopoulos, N., Jang, K., Stathatos, K. and Valluri, J., Integrated management of large satellite-terrestrial networks, Proceedings MILCOM, 383-387, Monterey, CA, USA, (1997).

[10] Chan, V.W.S., Some research directions for future integrated satellite and terrestrial networks, MILCOM - IEEE Military Communications Conference, 1-7, Orlando, FL, USA, (2007).

[11] $\mathrm{Hu}, \mathrm{J}$. and Song, T., A vehicle-mounted communication system integrating satellite and terrestrial networks, 7th International Conference on Computing and Convergence Technology (ICCCT), 767-771, Seoul, (2012).

[12] Sheriff, R.E. and Gardiner, J.G., Integrating satellite and terrestrial communication networks, IEE Colloquium on Mobile Communications, 1-7, London, UK, (1992).

[13] Moraitis, N. and Panagopoulos, A.D., On the interference analysis between terrestrial cellular and multiple airborne wireless networks, Proceedings of the 
5th European Conference on Antennas and Propagation (EUCAP), 13711375, Rome, (2011).

[14] Boria, F.J., A sensor platform capable of aerial and terrestrial locomotion, IEEE/RSJ International Conference on Intelligent Robots and Systems, 3959-3964, Edmonton, Alta, (2005).

[15] Vuran, M.C. and Akyildiz, I.F., Cross-layer packet size optimization for wireless terrestrial, underwater, and underground sensor networks, IEEE INFOCOM The 27th Conference on Computer Communications, 226-230, Phoenix, AZ, (2008).

[16] Sato, N., Oikawa, M., Suzuki, J., Ishikawa, T. and Murata, Y., Design and implementation of movie camera recording on worker's motion tracing system by terrestrial magnetism sensors, 13th International Conference on NetworkBased Information Systems, 451-456, Takayama, (2010).

[17] Sato, N., Oikawa, M., Takayama, T. and Murata, Y., An angle measurement method by using terrestrial magnetism sensors on a ski jumper's motion monitoring system, 14th International Conference on Network-Based Information Systems, 60-67, Tirana, (2011).

[18] Duan, S., Yu, Y. and Wang, Q., Monitoring and control of terrestrial pipe cathode protection system based on wireless sensor network, IET International Conference on Wireless Sensor Network (IET-WSN), 7-12, Beijing, (2010).

[19] Stuntebeck, E.P., Pompili, D. and Melodia, T., Wireless underground sensor networks using commodity terrestrial motes, 2nd IEEE Workshop on Wireless Mesh Networks, 112-114, Reston, VA, (2006).

[20] Alhashimi, A., Varagnolo, D. and Gustafsson, T., Calibrating Distance Sensors for Terrestrial Applications Without Groundtruth Information, IEEE Sensors Journal, 17, 2, 3698-3709, (2017).

[21] Tondwalkar, A.V. and Vinayakray-Jani, P., Terrestrial localization by using angle of arrival measurements in wireless sensor network, International Conference on Computational Intelligence and Communication Networks (CICN), 188-191, Jabalpur, (2015).

[22] https://www.riverbed.com/gb/, (06.02.2019). 